\title{
Self-Inhibitory Activity of Trichoderma Soluble Metabolites and Their Antifungal Effects on Fusarium oxysporum
}

\author{
Samuel Álvarez-García ${ }^{1, *(\mathbb{D}}$, Sara Mayo-Prieto ${ }^{1}\left(\mathbb{D}\right.$, Santiago Gutiérrez $^{2}(\mathbb{D}$ \\ and Pedro Antonio Casquero ${ }^{1}$ (D) \\ 1 Grupo Universitario de Investigación en Ingeniería y Agricultura Sostenible (GUIIAS), \\ Instituto de Medio Ambiente, Recursos Naturales y Biodiversidad, Universidad de León, \\ Avenida Portugal 41, 24071 León, Spain; smayp@unileon.es (S.M.-P.); pacas1@unileon.es (P.A.C.) \\ 2 Grupo Universitario de Investigación en Ingeniería y Agricultura Sostenible (GUIIAS), \\ Área de Microbiología, Escuela de Ingeniería Agraria y Forestal, Universidad de León, \\ Campus de Ponferrada, Avenida Astorga s/n, 24401 Ponferrada, Spain; s.gutierrez@unileon.es \\ * Correspondence: salvg@unileon.es
}

Received: 1 August 2020; Accepted: 15 September 2020; Published: 17 September 2020

\begin{abstract}
Self-inhibitory processes are a common feature shared by different organisms. One of the main mechanisms involved in these interactions regarding microorganisms is the release of toxic diffusible substances into the environment. These metabolites can exert both antimicrobial effects against other organisms as well as self-inhibitory ones. The in vitro evaluation of these effects against other organisms has been widely used to identify potential biocontrol agents against phytopathogenic microorganisms. In the present study, we performed membrane assays to compare the self-inhibitory effects of soluble metabolites produced by several Trichoderma isolates and their antifungal activity against a phytopathogenic strain of Fusarium oxysporum. The results demonstrated that Trichoderma spp. present a high self-inhibitory activity in vitro, being affected in both their growth rate and the macroscopic structure of their colonies. These effects were highly similar to those exerted against F. oxysporum in the same conditions, showing no significant differences in most cases. Consequently, membrane assays may not be very informative by themselves to assess putative biocontrol capabilities. Therefore, different methods, or a combination of antifungal and self-inhibitory experiments, could be a better approach to evaluate the potential biocontrol activity of microbial strains in order to pre-select them for further in vivo trials.
\end{abstract}

Keywords: self-inhibition; autotoxicity; autoinhibition; membrane assay; secondary metabolites; diffusible metabolites; antifungal; fungi; Trichoderma; Fusarium

\section{Introduction}

Autotoxicity and self-inhibition have been described as common traits shown by different species, genera, and kingdoms [1]. Some general mechanisms have been proposed to explain these processes, mainly the accumulation and release of different toxic compounds to the environment, and also the self-inhibitory activity of extracellular self-DNA or conspecific DNA [1]. However, competition for resources, quorum sensing, and reproductive issues have been pointed out as the most likely and major ecological factors that motivate this behavior [2].

Regarding filamentous fungi, some studies have been conducted to evaluate self-inhibitory processes, allowing the identification of different autotoxic compounds [3,4]. Nonetheless, most of these studies are focused on the concentration-dependent self-inhibition of fungal spore germination [3-5]. Moreover, autotoxicity has been proposed as a way to drive directional growth, accounting for the 
characteristic radial expansion of fungal colonies [6]. As for the genus Trichoderma, there are very few references to self-inhibition. In this regard, most significant studies point to the self-inhibitory effects of Trichoderma harzianum mediated by extracellular self-DNA [1]. Besides, to our knowledge, there are no previous studies comparing self-inhibitory and antifungal effects produced in vitro by Trichoderma spp. or any other biocontrol agent. Trichoderma is a ubiquitous genus of filamentous fungi, widely used as a biocontrol agent against many phytopathogenic microorganisms $[7,8]$, as well as for crop biostimulation $[9,10]$ and as a general model to sustain crop productivity [11].

On the other hand, Fusarium oxysporum is a common endophyte and phytopathogenic filamentous fungus that thrives in numerous important crops [12], F. oxysporum f. sp. phaseoli being one of the forms that mainly affects bean plants (Phaseolus vulgaris L.) [13]. Furthermore, many studies highlight the antifungal activity of soluble metabolites $[8,14,15]$, as well as volatile ones $[5,14,16]$, produced by Trichoderma spp. against different Fusarium species.

The hypothesis of this work is that soluble metabolites released in vitro by Trichoderma spp. produce both self-inhibitory effects and antifungal effects against $F$. oxysporum. The main objective of the present study is to evaluate the self-inhibitory effects of soluble metabolites produced by several Trichoderma isolates and to compare them to the antifungal activity exerted by the same fungal strains against a phytopathogenic strain of F. oxysporum.

\section{Materials and Methods}

\subsection{Microbial Strains and Culture Conditions}

Ten Trichoderma strains were used to evaluate the activity of their diffusible metabolites: seven T. harzianum, one T. citrinoviride, one T. velutinum, and one T. gamsii. Out of the ten strains, eight of them were isolated from bean (P. vulgaris L.) fields belonging to de Protected Geographical Indication (PGI) "Alubia de La Bañeza-León", while the other two were isolated from sugar beet crops growing in the same area [17]. Trichoderma strains were selected in such a way that at least either the fungal species, the place of origin, the bean variety (or crop) they came from, or the source they were isolated from (seed or soil) differed among them (Table 1).

A strain of F. oxysporum (F3 from now onwards) was isolated from bean (P. vulgaris) fields belonging to the same PGI and was selected for its high virulence against this crop.

All fungal strains were preserved in $50 \%$ glycerol spore suspension at $-80^{\circ} \mathrm{C}$ and stored in the "Pathogens and Antagonists Collection" at the "Pest and Diseases Diagnosis Laboratory" (PALDPD, University of León, León, Spain). All cultures were activated on PDA (Sigma Aldrich, St. Louis, MO, USA) at $25^{\circ} \mathrm{C}$.

Table 1. Code, species, source, and area of origin of the Trichoderma isolates used in the assays.

\begin{tabular}{cccccc}
\hline Code & Trichoderma Species & Crop & Source & Municipality & Area \\
\hline T002 & T. harzianum & Riñón menudo (bean) & seed & Moscas del Páramo & El Páramo \\
T007 & T. harzianum & Pinta (bean) & seed & Sueros de Cepeda & Astorga \\
T008 & T. citrinoviride & Pinta (bean) & seed & Fresno de la Vega & Esla-Campos \\
T015 & T. harzianum & Riñón menudo (bean) & seed & Veguellina de Fondo & El Páramo \\
T021 & T. harzianum & Pinta (bean) & seed & Altobar de la Encomienda & El Páramo \\
T028 & T. velutinum & Riñón (bean) & soil & Otero de Escarpizo & Astorga \\
T044 & T. harzianum & Riñón (bean) & soil & Javares de los Oteros & Esla-Campos \\
T050 & T. harzianum & Canela (bean) & soil & Bercianos del Páramo & El Páramo \\
T055 & T. harzianum & Sugarbeet & soil & La Milla del Páramo & El Páramo \\
T057 & T. gamsii & Sugarbeet & soil & La Milla del Páramo & El Páramo \\
\hline
\end{tabular}

\subsection{In Vitro Evaluation of Antifungal and Self-Inhibitory Activity of Soluble Metabolites Produced by} Trichoderma spp.

A membrane assay was performed, as described by Mayo et al. (2015) [7], by placing a sterile cellophane membrane to cover the potato-dextrose-agar (PDA, Sigma Aldrich, St. Louis, MO, USA) medium in $90 \mathrm{~mm}$ Petri dishes (Sigma-Aldrich Chemie GmbH, Steinheim, Germany). A 6 mm plug from 
the edge of a 2 day-old Trichoderma culture was placed in the center of each plate over the cellophane and was grown for 2 days, letting the soluble metabolites diffuse to the medium, yet avoiding its colonization by the fungal mycelium. After that, membrane and fungi were removed, and a $6 \mathrm{~mm}$ mycelial plug from the edge of the 2 day-old culture of the same Trichoderma strain was placed in the center of the dish. Controls were performed in the same manner but without growing Trichoderma over the membranes prior to the inoculation. Diameters of the colonies were measured in three different directions with a ruler to the farthest edge of mycelial growth (via visual detection of the most outer hyphal apex) 24 and $48 \mathrm{~h}$ post-inoculation (hpi) (Figure 1a). The diameter of each replicate was considered as the mean of its three measurements. The second round of data collection was determined to be $48 \mathrm{hpi}$, taking into account that the fastest-growing Trichoderma strains reached the edge of the plate at this time.

The inhibitory activity of Trichoderma metabolites on F. oxysporum was performed as described above, but inoculating a $6 \mathrm{~mm}$ plug from the edge of a 5 day-old $F$. oxysporum culture on the center of the plates after removing the membranes. The diameters of the colonies were measured in the same way, but 3 and 7 days post-inoculation (dpi) (Figure 1b), as the slower mycelial growth of F. oxysporum controls reached the same diameter after 3 and 7 days as Trichoderma controls after 24 and $48 \mathrm{~h}$. The second round of data collection was determined to be $7 \mathrm{dpi}$, taking into account that F3 colonies reached the edge of the plate at this time. From now onwards, measures taken $24 \mathrm{hpi}$ for Trichoderma spp. and 3 dpi for F3 will be referred to as the first round of data collection, while 48 hpi for Trichoderma spp. and 7 dpi for F3 will be considered to be the second round of data collection, in order to compare self and heterologous inhibition.

Self-inhibitory and antifungal membrane assays

(a)
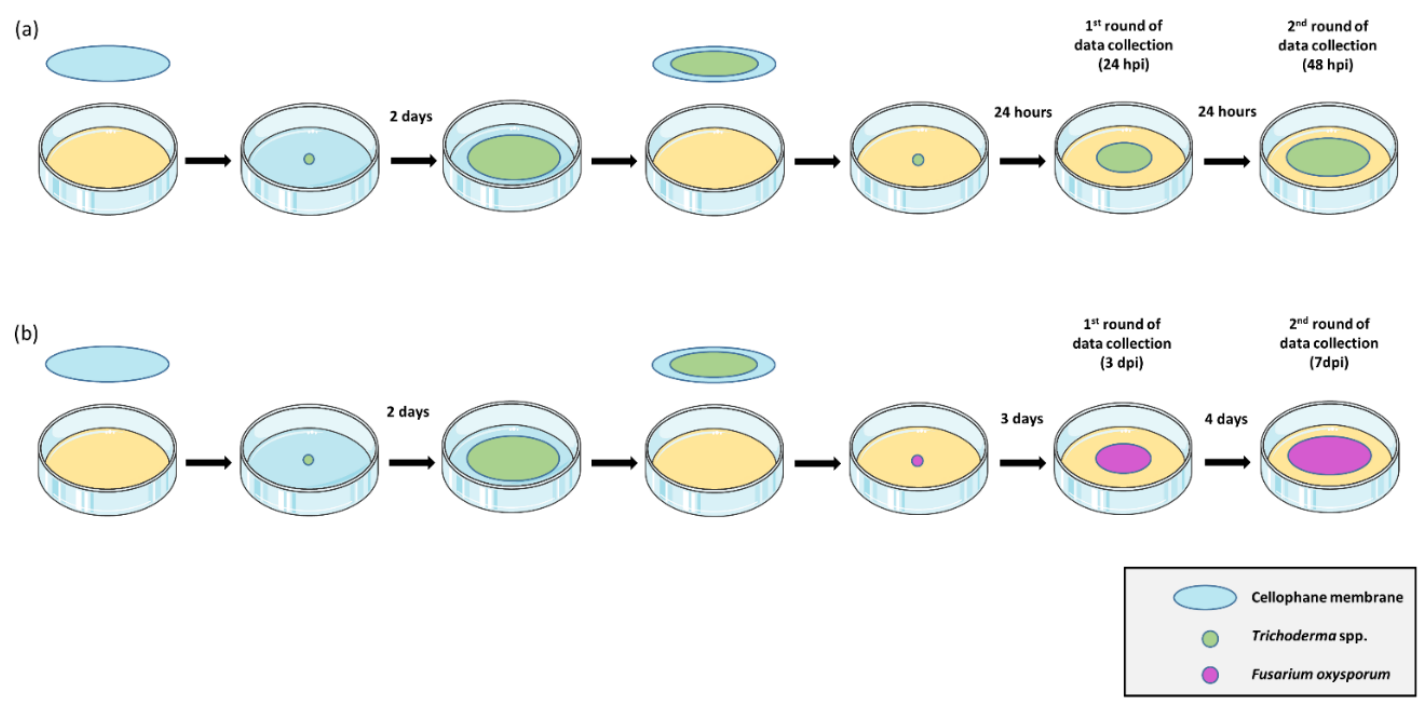

Figure 1. Self-inhibitory and antifungal membrane assays. (a) Evaluation of the effects of Trichoderma spp. diffusible metabolites on the same Trichoderma strain. (b) Evaluation of the effects of Trichoderma spp. diffusible metabolites on F. oxysporum $\mathrm{F} 3$.

Controls were performed in the same manner but without growing Trichoderma spp. over the cellophane membrane. The 1st round of data collection was performed when fungal colonies in the controls reached $1 / 3$ of the plate ( 24 hpi for Trichoderma spp. and 3 dpi for F. oxysporum). The 2 nd round of data collection was performed when fungal colonies in the controls reached the edge of the plate (48 hpi for the fastest Trichoderma spp. and $7 \mathrm{dpi}$ for F. oxysporum). Diameters were measured with a ruler in three different directions. Four replicates per treatment were performed. All cultures were performed on PDA (Sigma Aldrich, St. Louis, MO, USA) at $25{ }^{\circ} \mathrm{C}$. 


\subsection{Data Treatment and Statistical Analysis}

Microbial growth was considered as the mean diameter of the three measures from each replicate, and $6 \mathrm{~mm}$ were subtracted from all measures to avoid distortions produced in the percentage of inhibition (PI) by the diameter of the plugs, as shown by Mutawila et al. (2016) [15]. PIs were estimated in relation to the control using the following equation: $\mathrm{PI}(\%)=[(\mathrm{C}-\mathrm{T} / \mathrm{C}) \times 100][16]$, where $\mathrm{C}$ is the diameter of the control and $\mathrm{T}$ is that of each Trichoderma treatment. PIs were analyzed with one-way analysis of variance (ANOVA, $p \leq 0.05$ ) after confirmation of normality and equality of variances. Subsequently, treatments were contrasted between them and with their controls using Tukey's post hoc test $(p \leq 0.05)$. Statistical analyses were performed separately for self-inhibition and antifungal activity of the ten Trichoderma spp. (Table 2), as well as to compare self-inhibition and antifungal activity of each Trichoderma isolate (Figure 2). Four replicates were performed for each treatment.

\section{Results and Discussion}

Under the referred conditions, all Trichoderma isolates showed important antifungal effects on F3 growth (Table 2). T. harzianum isolates consistently demonstrated a higher inhibitory activity than the other three Trichoderma species, with PIs ranging from $99.51 \%$ to $86.92 \%$ at day 3 post-inoculation, and from $95.25 \%$ to $89.40 \%$ in day 7 post-inoculation. In contrast, T. citrinoviride T008 showed lower PI values (70.73\% in day 3 and 59.38\% in day 7), while T. velutinum T028 exerted the lowest inhibition of all strains, with $34.15 \%$ in day 3 and a mere $15.89 \%$ in day 7 . Finally, T. gamsii T057 showed similar PI to those of some T. harzianum in day $3(92.90 \%)$ with a significant decrease in day 7 (76.27\%). All treatments showed significant differences $(p \leq 0.05)$ compared to the growth of F3 controls. These results are in accordance with previous studies regarding the antifungal activity of Trichoderma spp. on F. oxysporum [18,19].

Table 2. PI values (\%) of self-inhibition and F3 inhibition produced by Trichoderma isolates. Results are expressed as the mean \pm standard deviation (SD) of PI (\%) from the four replicates. First round of data collection (24 hpi for Trichoderma spp. and 3 dpi for F3), and Second round of data collection (48 hpi for Trichoderma spp. and 7 dpi for F3).

\begin{tabular}{|c|c|c|c|c|c|c|c|c|c|}
\hline \multirow[b]{2}{*}{ Code } & \multirow[b]{2}{*}{ Trichoderma } & \multicolumn{4}{|c|}{ First Round of Data Collection } & \multicolumn{4}{|c|}{ Second Round of Data Collection } \\
\hline & & $\begin{array}{l}\text { Self-Inhibition } \\
\quad(\% \pm \text { SD) }\end{array}$ & Statistics ${ }^{1}$ & $\begin{array}{l}\text { F3 Inhibition } \\
(\% \pm \text { SD) }\end{array}$ & Statistics $^{2}$ & $\begin{array}{l}\text { Self-Inhibition } \\
\quad(\% \pm \text { SD) }\end{array}$ & Statistics ${ }^{1}$ & $\begin{array}{l}\text { F3 Inhibition } \\
\quad(\% \pm \text { SD) }\end{array}$ & Statistics $^{2}$ \\
\hline T002 & T. harzianum & $93.18 \pm 1.21$ & A & $99.51 \pm 0.56$ & $\mathrm{a}$ & $95.04 \pm 0.87$ & A & $95.25 \pm 1.89$ & $\mathrm{a}$ \\
\hline T007 & T. harzianum & $91.68 \pm 1.89$ & $\mathrm{~A}, \mathrm{~B}$ & $98.54 \pm 1.26$ & a & $89.87 \pm 2.67$ & $\mathrm{~A}, \mathrm{~B}$ & $92.93 \pm 2.16$ & $a, b$ \\
\hline T008 & T. citrinoviride & $74.51 \pm 1.66$ & $\mathrm{D}$ & $70.73 \pm 1.38$ & e & $71.02 \pm 1.85$ & $\mathrm{C}$ & $59.38 \pm 2.93$ & $\mathrm{~d}$ \\
\hline T015 & T. harzianum & $93.86 \pm 1.60$ & A & $97.07 \pm 1.59$ & $a, b$ & $94.62 \pm 1.21$ & A & $89.40 \pm 2.28$ & $\mathrm{~b}$ \\
\hline T021 & T. harzianum & $91.43 \pm 3.77$ & $\mathrm{~A}, \mathrm{~B}$ & $99.02 \pm 0.00$ & $\mathrm{a}$ & $90.08 \pm 4.25$ & $\mathrm{~A}, \mathrm{~B}$ & $92.38 \pm 0.91$ & $a, b$ \\
\hline T028 & T. velutinum & $42.29 \pm 1.40$ & $\mathrm{E}$ & $34.15 \pm 3.03$ & $\mathrm{f}$ & $23.57 \pm 2.12$ & $\mathrm{D}$ & $15.89 \pm 1.96$ & $\mathrm{e}$ \\
\hline T044 & T. harzianum & $90.09 \pm 1.79$ & $\mathrm{~A}, \mathrm{~B}$ & $91.35 \pm 2.55$ & $c, d$ & $89.66 \pm 1.71$ & $\mathrm{~A}, \mathrm{~B}$ & $92.93 \pm 3.22$ & $a, b$ \\
\hline T050 & T. harzianum & $91.11 \pm 1.48$ & $\mathrm{~A}, \mathrm{~B}$ & $88.91 \pm 0.51$ & $c, d$ & $89.98 \pm 0.94$ & $\mathrm{~A}, \mathrm{~B}$ & $93.46 \pm 0.42$ & $a, b$ \\
\hline T055 & T. harzianum & $87.86 \pm 0.97$ & B & $86.92 \pm 1.12$ & $\mathrm{~d}$ & $87.66 \pm 1.35$ & B & $90.40 \pm 1.11$ & $a, b$ \\
\hline T057 & T. gamsii & $82.53 \pm 2.91$ & $\mathrm{C}$ & $92.90 \pm 4.86$ & $\mathrm{~b}, \mathrm{c}$ & $68.74 \pm 3.65$ & $\mathrm{C}$ & $76.27 \pm 2.02$ & c \\
\hline
\end{tabular}

Interestingly, the self-inhibitory effects of the tested Trichoderma strains seem to be highly similar to the abovementioned antifungal inhibitory ones on F3. In this regard, five strains (T008, T015, T044, T050, and T055) showed no significant differences between self-inhibitory and antifungal activities during the first round of data collection (Figure 2a). Moreover, this number amounted to seven strains (all T. harzianum tested) in the second round of data collection (Figure $2 \mathrm{~b}$ ). The remaining three Trichoderma strains (T008, T028 and T057) showed, however, differences between self and heterologous inhibition, although following a similar trend. Their IPs for both heterologous antifungal and self-inhibitory effects were significantly lower $(p \leq 0.05)$ than those of the T. harzianum strains (Table 2). Self-inhibitory PIs of T. harzianum strains were very high and ranged from 95.04\% (T002, 
$48 \mathrm{hpi}$ ) to $87.66 \%$ (T055, $48 \mathrm{hpi}$ ). However, T008, T028, and T057 showed, respectively, self-inhibitory PIs of $74.51 \%, 42.29 \%$, and $82.53 \%$ after $24 \mathrm{~h}$, and $71.02 \%, 23.57 \%$ and $68.74 \%$ after $48 \mathrm{~h}$ (Table 2 ). Additionally, T008 and T028 were the only two strains showing significantly higher self-inhibition than antifungal inhibition against F3. Other strains showed slightly higher self-inhibitory effects than their antifungal ones, but were not statistically significant $(p \leq 0.05)$ (Figure 2).
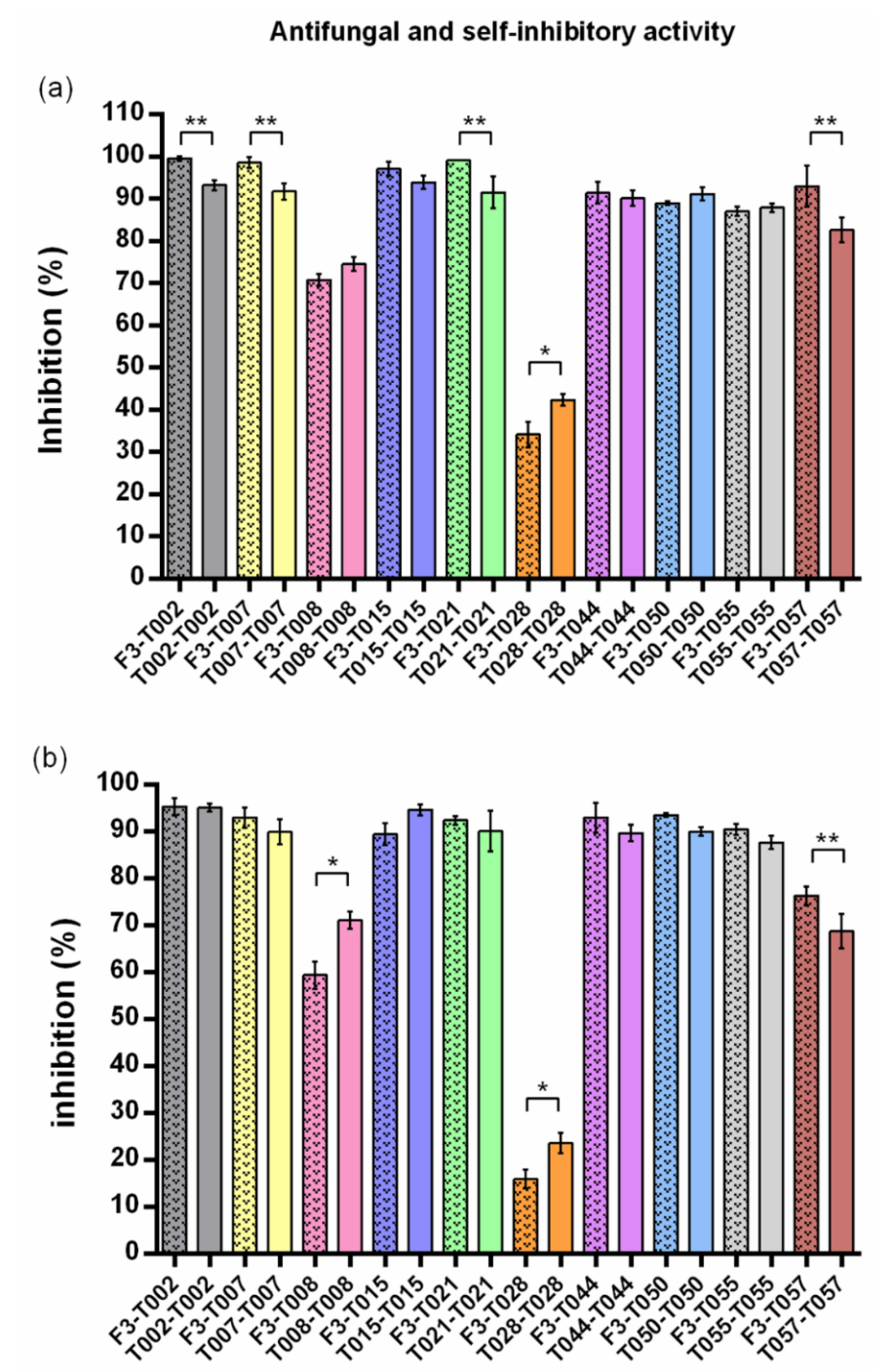

Figure 2. Self-inhibitory activity of the soluble metabolites from the Trichoderma spp. evaluated (plain columns), and their antifungal activity against F. oxysporum F3 (shadowed columns). (a) First round of data collection (24 hpi for Trichoderma and 3 dpi for F3); (b) Second round of data collection (48 hpi for Trichoderma and $7 \mathrm{dpi}$ for F3). Columns indicate the mean of PI values (\%) and their standard deviation (SD). Each color represents a treatment with a different Trichoderma strain. Shadowed columns represent PI values produced by Trichoderma strains against F3, while plain ones represent self-inhibitory PI values produced by each Trichoderma strain on itself. $\left({ }^{*}\right)$ indicate significantly higher antifungal than self-inhibitory activity $(p \leq 0.05)$ within the same Trichoderma isolate. $\left({ }^{* *}\right)$ indicate significantly higher self-inhibitory than antifungal activity $(p \leq 0.05)$ within the same Trichoderma isolate. No asterisks mean no differences between self-inhibitory and antifungal activity $(p \leq 0.05)$. PIs were estimated in relation to the control using the following equation: PI $(\%)=[(C-T / C) \times 100][16]$. A one-way analysis of variance (ANOVA, $p \leq 0.05$ ) was performed, and differences were estimated using Tukey's post hoc test $(p \leq 0.05)$ to compare the self-inhibition and antifungal effects for each Trichoderma strain. 
These results seem to indicate that the antifungal and self-inhibitory effects exerted in vitro by Trichoderma spp. are closely related and might be general traits shared for both heterologous competition with other fungal species in the environment, as well as ecological adaptations within the same genus, species, and strain. The latter likely being related to directional centrifugal growth of filamentous fungi [6], competition for resources, and/or reproductive processes [3]. The self-inhibitory activity presented here seems to be a non-specific one, and therefore, different from that proposed by Mazzoleni et al. (2015) in T. harzianum, mediated by conspecific DNA [1]. These heterologous and autotoxic effects may be related to those observed in fairy-ring-forming basidiomycetes, which have been proposed as one of the mechanisms behind the formation of their characteristic growth rings in the soil and their important influence on the ecosystemic scale [20]. The highly similar effects observed between F3 inhibition and Trichoderma self-inhibition may be partly due to their relative phylogenetic and ecological proximity, being both soilborne filamentous ascomycetes related to the rhizosphere and plants, as epiphytic or endophytic fungi. New studies are needed to elucidate whether these similar effects are also found when comparing other filamentous fungi and less related microorganisms.

The results also point out that self-inhibition varies between Trichoderma strains and species, suggesting that either they produce higher quantity and/or stronger autotoxic metabolites, or they possess different detoxification capabilities to confront these compounds. We propose that, taking into account the similarities presented here between self and heterologous antifungal inhibitory effects within the same strains, the differences seen between strains are mostly due to different antifungal activity and/or the amount rather than different detoxification capabilities. Besides, the high PI values, especially regarding those referred to self-inhibition, are likely due to an extremely high accumulation of soluble metabolites in the PDA medium, derived from the unnatural conditions of the in vitro design. Nevertheless, with the available data, it is not possible to determine whether the observed effects are produced by toxic subproducts of fungal metabolism or secondary metabolites that are purposefully released for antifungal activity. It also is not possible to assure that both the self-inhibitory and the heterologous antifungal activities are produced by the same metabolites, even though the very similar PI values between them seem to point in this direction. New studies should be directed to elucidate these aspects.

In addition, as can be seen in Figure 3, Trichoderma colonies suffered a clearly aberrant growth when exposed to their own diffusible metabolites, showing uncharacteristic arbuscular shapes instead of their common circular colonies with homogeneous edges, clearly observed seven days after inoculation. This aberrant growth in the macroscopic level may indicate microscopic, anatomical abnormalities in the fungal hyphae, as well as physiological alterations [21,22]. Further microscopic and molecular investigations are needed to unveil these anatomical and physiological traits.

It is well known that in vitro assays are only an approximation of more complex natural contexts [23] and that, at least in the field of biological control and microbial interactions, they always need to be completed and validated by subsequent in vivo trials $[7,17]$. Nevertheless, the overall results here presented pose an additional doubt on membrane assays, and perhaps, on other in vitro related methods used to evaluate fungal soluble metabolites. These experiments are widely used as preliminary studies to help identify new bioactive compounds or microbiological strains with potential biocontrol capabilities [23-26]. However, our findings suggest that membrane assays, at least in the reported conditions, do not seem to be a very informative in vitro indicator of the real biocontrol activity that a fungal strain may exert in natural conditions. Therefore, these assays would still be very useful to identify bioactive compounds, but not so much to select putative biocontrol strains. In this regard, taking into account that most Trichoderma strains tested in the present study showed no significant differences between their self-inhibitory activity and their antifungal activity against F. oxysporum, we believe that their high in vitro inhibitory activity alone is not enough to claim a potential biocontrol activity, being likely biased by the unnatural concentrations reached in the plates. Thus, different experimental laboratory designs could be more adequate to evaluate these traits before transitioning to 
in vivo and field trials. For example, Kron et al. (2020) [27] demonstrated that ex vivo assays using Pseudomonas orientalis mutants against Erwinia amylovora were more informative than in vitro assays.

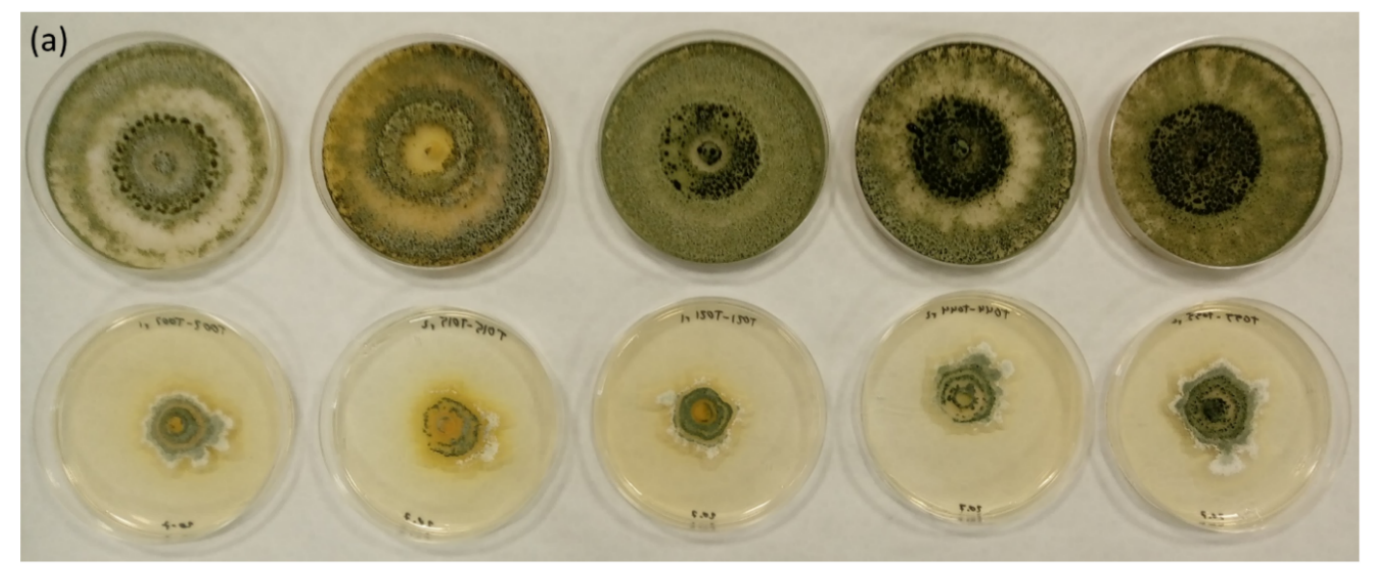

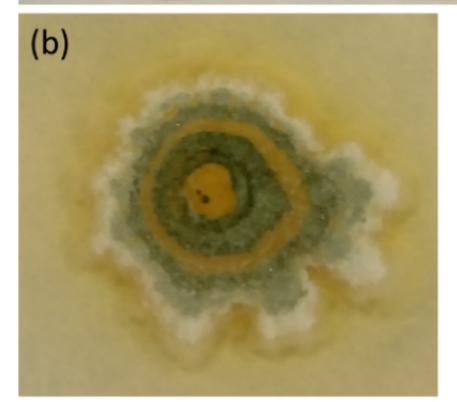

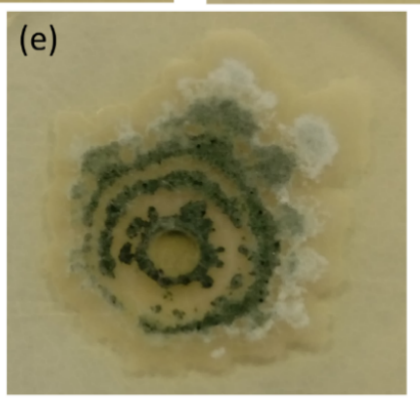

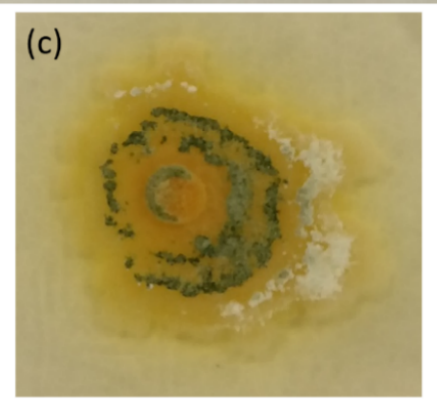
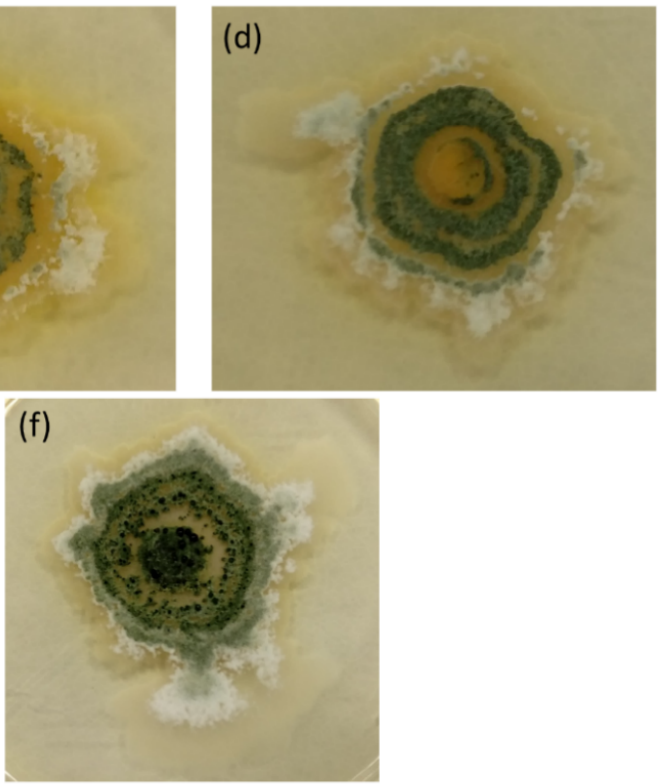

Figure 3. Development of some Trichoderma colonies after 7 days growing on PDA medium with soluble metabolites produced by the strain itself. Aberrant arbuscular shapes can be seen in the treatments. (a) Controls without metabolites (upper row; left to right: T002, T015, T021, T044, and T055); Trichoderma treatments (lower row; left to right: T002, T015, T021, T044, and T055), (b) T002 detail, (c) T015 detail, (d) T021 detail, (e) T044 detail, and (f) T055 detail.

In addition, we suggest that if membrane assays are used to identify potential biocontrol strains, autotoxic studies, as the here presented using the same strains, should be conducted in identical conditions in order to compare and select those microbial agents showing both high antimicrobial activity alongside a lower self-inhibitory one. For example, in our case, while T002, T007, T015, and T021 show very high antifungal effects on the first round of data collection, we may consider discarding T015 as a potential biocontrol strain, as its antifungal activity against F3 is not significantly different from its own self-inhibitory one (Figure 2a). However, during the second round of data collection, T057 was the only strain showing significantly higher heterologous than self-inhibitory effects (Figure $2 b$ ). Thus, even though it had a lower antifungal activity than other strains, it might be adequate to select it for further in planta or in vivo experiments. This is further supported by the fact that T057 strain showed the highest difference between antifungal and self-inhibitory activities during the first round (Figure 2a). However, the validity of these hypotheses and proposals need to be 
tested by future plant and field trials, as well as by using a wider variety of both biocontrol agents and phytopathogenic strains to assess the presence of the same traits in other microorganisms.

Finally, a deeper understanding of self-inhibitory mechanisms within biocontrol strains, species, and genera might be a key factor to develop commercial pesticides based on a mixture of similar biological control agents. Additionally, this knowledge would be very useful to determine the ideal concentration of the agent when applying it on the field in order to avoid self-inhibitory effects, as well as to select the adequate growth conditions for its industrial production.

\section{Conclusions}

To summarize, the results presented demonstrate that the majority of the tested Trichoderma spp. show, in vitro, a high self-inhibitory activity mediated by secreted soluble metabolites. This activity varied among different strains and species, with $T$. harzianum showing the highest self-inhibitory effects. Trichoderma strains are affected both in their growth rate and the macroscopic structure of their colonies, arguably reflecting microscopic structural and physiological abnormalities in the fungal hyphae. These growth-inhibitory effects are highly similar to those exerted against Fusarium oxysporum in the same conditions, especially for T. harzianum isolates, indicating a likely comparable mechanism in both cases. In this regard, the great inhibition observed in both cases for most Trichoderma strains is possibly derived from the extremely high concentration of metabolites accumulated in the culture medium. As a result, membrane assays seem to not be very informative by themselves, in regards the direct biocontrol capabilities of the tested strains. Therefore, different methods or a combination of antifungal and self-inhibitory experiments could be a better approach to preliminarily evaluate the potential biocontrol activity of microbial strains in order to pre-select them in vitro for further in vivo trials. This strategy may serve to optimize the process of pre-selection, helping to save time and resources in the subsequent phases of the research. Nevertheless, these conclusions need to be further investigated and confirmed by new assays, involving both in vivo studies and a wider variety of biocontrol and phytopathogenic microbial strains.

Author Contributions: Conceptualization, S.Á.-G. and P.A.C.; methodology, S.G. and S.M.-P.; validation, P.A.C. and S.G.; formal analysis, P.A.C.; investigation, S.Á.-G.; resources, S.M.-P. and S.G.; data curation, S.Á.-G.; writing_original draft preparation, S.Á.-G.; writing—review and editing, S.Á.-G., S.M.-P., S.G. and P.A.C.; supervision, P.A.C. and S.G.; project administration, P.A.C.; funding acquisition, P.A.C. All authors have read and agreed to the published version of the manuscript.

Funding: This research was funded by Junta de Castilla y León, Consejería de Educación for the project "Application of Trichoderma strains in sustainable quality bean production"; (LE251P18) and for the grant to Samuel Álvarez García of the Junta de Castilla y León according to ORDER EDU/529/2017, of June 26, co-financed by the European Social Fund. The research has been funded also by the University of León: Universidad de León; Convocatoria de ayudas para el fomento de la publicación en acceso abierto a profesores de nueva incorporación; programa 463A.3.01.

Acknowledgments: Junta de Castilla y León, Consejería de Educación for the project "Application of Trichoderma strains in sustainable quality bean production; (LE251P18) Universidad de León.

Conflicts of Interest: The authors declare no conflict of interest. The funders had no role in the design of the study; in the collection, analyses, or interpretation of data; in the writing of the manuscript, or in the decision to publish the results.

\section{References}

1. Mazzoleni, S.; Cartenì, F.; Bonanomi, G.; Senatore, M.; Termolino, P.; Giannino, F.; Incerti, G.; Rietkerk, M.; Lanzotti, V.; Chiusano, M.L. Inhibitory effects of extracellular self-DNA: A general biological process? New Phytol. 2015, 206, 127-132. [CrossRef] [PubMed]

2. Hogan, D.A. Talking to themselves: Autoregulation and quorum sensing in fungi. Eukaryot. Cell 2006, 5, 613-619. [CrossRef] [PubMed]

3. Gillot, G.; Decourcelle, N.; Dauer, G.; Barbier, G.; Coton, E.; Delmail, D.; Mounier, J. 1-Octanol, a self-inhibitor of spore germination in Penicillium camemberti. Food Microbiol. 2016, 57, 1-7. [CrossRef] [PubMed] 
4. Polyanskaya, L.M.; Tolstikhina, T.E.; Kochkina, G.A.; Ivanushkina, N.E.; Zvyagintsev, D.G. Regularities in the germination of conidia of phytopathogenic fungi. Microbiology 2004, 73, 383-388. [CrossRef]

5. Chitarra, G.S.; Abee, T.; Rombouts, F.M.; Posthumus, M.A.; Dijksterhuis, J. Germination of Penicillium paneum conidia is regulated by 1-octen-3-ol, a volatile self-inhibitor. Appl. Environ. Microbiol. 2004, 70, 2823-2829. [CrossRef]

6. Bottone, E.J.; Nagarsheth, N.; Chiu, K. Evidence of self-inhibition by filamentous fungi accounts for unidirectional hyphal growth in colonies. Can. J. Microbiol. 1998, 44, 390-393. [CrossRef]

7. Mayo, S.; Gutiérrez, S.; Malmierca, M.G.; Lorenzana, A.; Campelo, M.P.; Hermosa, R.; Casquero, P.A. Influence of Rhizoctonia solani and Trichoderma spp. in growth of bean (Phaseolus vulgaris L.) and in the induction of plant defense-related genes. Front. Plant Sci. 2015, 6. [CrossRef]

8. Zachow, C.; Berg, C.; Müller, H.; Monk, J.; Berg, G. Endemic plants harbour specific Trichoderma communities with an exceptional potential for biocontrol of phytopathogens. J. Biotechnol. 2016, 235, 162-170. [CrossRef]

9. Szczałba, M.; Kopta, T.; Gąstoł, M.; Sękara, A. Comprehensive insight into arbuscular mycorrhizal fungi, Trichoderma spp. and plant multilevel interactions with emphasis on biostimulation of horticultural crops. J. Appl. Microbiol. 2019, 127, 630-647. [CrossRef]

10. Contreras-Cornejo, H.A.; Macías-Rodríguez, L.; Del-Val, E.; Larsen, J. Ecological functions of Trichoderma spp. and their secondary metabolites in the rhizosphere: Interactions with plants. FEMS Microbiol. Ecol. 2016, 92, fiw036. [CrossRef]

11. Kashyap, P.L.; Rai, P.; Srivastava, A.K.; Kumar, S. Trichoderma for climate resilient agriculture. World J. Microbiol. Biotechnol. 2017, 33, 155. [CrossRef]

12. de Lamo, F.J.; Takken, F.L.W. Biocontrol by Fusarium oxysporum Using Endophyte-Mediated Resistance. Front. Plant Sci. 2020, 11, 37. [CrossRef]

13. de Borba, M.C.; Garcés-Fiallos, F.R.; Stadnik, M.J. Reactions of black bean seedlings and adult plants to infection by Fusarium oxysporum f. sp. phaseoli. Crop Prot. 2017, 96, 221-227. [CrossRef]

14. Li, N.; Alfiky, A.; Wang, W.; Islam, M.; Nourollahi, K.; Liu, X.; Kang, S. Volatile Compound-Mediated Recognition and Inhibition Between Trichoderma Biocontrol Agents and Fusarium oxysporum. Front. Microbiol. 2018, 9, 1-16. [CrossRef]

15. Mutawila, C.; Vinale, F.; Halleen, F.; Lorito, M.; Mostert, L. Isolation, production and in vitro effects of the major secondary metabolite produced by Trichoderma species used for the control of grapevine trunk diseases. Plant Pathol. 2016, 65, 104-113. [CrossRef]

16. Gotor-Vila, A.; Teixidó, N.; Di Francesco, A.; Usall, J.; Ugolini, L.; Torres, R.; Mari, M. Antifungal effect of volatile organic compounds produced by Bacillus amyloliquefaciens CPA-8 against fruit pathogen decays of cherry. Food Microbiol. 2017, 64, 219-225. [CrossRef]

17. Mayo-Prieto, S.; Campelo, M.P.; Lorenzana, A.; Rodríguez-González, A.; Reinoso, B.; Gutiérrez, S.; Casquero, P.A. Antifungal activity and bean growth promotion of Trichoderma strains isolated from seed vs soil. Eur. J. Plant Pathol. 2020. [CrossRef]

18. Carvalho, D.D.C.; Lobo Júnior, M.; Martins, I.; Inglis, P.W.; Mello, S.C.M. Biological control of Fusarium oxysporum f. sp. phaseoli by Trichoderma harzianum and its use for common bean seed treatment. Trop. Plant Pathol. 2014, 39, 384-391. [CrossRef]

19. John, R.P.; Tyagi, R.D.; Prévost, D.; Brar, S.K.; Pouleur, S.; Surampalli, R.Y. Mycoparasitic Trichoderma viride as a biocontrol agent against Fusarium oxysporum f. sp. adzuki and Pythium arrhenomanes and as a growth promoter of soybean. Crop Prot. 2010, 29, 1452-1459. [CrossRef]

20. Zotti, M.; De Filippis, F.; Cesarano, G.; Ercolini, D.; Tesei, G.; Allegrezza, M.; Giannino, F.; Mazzoleni, S.; Bonanomi, G. One ring to rule them all: An ecosystem engineer fungus fosters plant and microbial diversity in a Mediterranean grassland. New Phytol. 2020. [CrossRef]

21. Mucha, J.; Zadworny, M.; Werner, A. Cytoskeleton and mitochondrial morphology of saprotrophs and the pathogen Heterobasidion annosum in the presence of Suillus bovinus metabolites. Mycol. Res. 2009, 113, 981-990. [CrossRef]

22. Mucha, J. Changes in hyphal morphology and activity of phenoloxidases during interactions between selected ectomycorrhizal fungi and two species of Trichoderma. Antonie Leeuwenhoek Int. J. Gen. Mol. Microbiol. 2011, 100, 155-160. [CrossRef] [PubMed] 
23. Carrero-Carrón, I.; Trapero-Casas, J.L.; Olivares-García, C.; Monte, E.; Hermosa, R.; Jiménez-Díaz, R.M. Trichoderma asperellum is effective for biocontrol of Verticillium wilt in olive caused by the defoliating pathotype of Verticillium dahliae. Crop Prot. 2016, 88. [CrossRef]

24. Jensen, B.D.; Knorr, K.; Nicolaisen, M. In vitro competition between Fusarium graminearum and Epicoccum nigrum on media and wheat grains. Eur. J. Plant Pathol. 2016, 146, 657-670. [CrossRef]

25. Taghdi, Y.; Hermosa, R.; Domínguez, S.; Rubio, M.B.; Essalmani, H.; Nicolás, C.; Monte, E. Effectiveness of composts and Trichoderma strains for control of Fusarium wilt of tomato. Phytopathol. Mediterr. 2015, 54, 232-240. [CrossRef]

26. Malmierca, M.G.; Cardoza, R.E.; Alexander, N.J.; McCormick, S.P.; Hermosa, R.; Monte, E.; Gutiérrez, S. Involvement of Trichoderma trichothecenes in the biocontrol activity and induction of plant defense-related genes. Appl. Environ. Microbiol. 2012, 78, 4856-4868. [CrossRef]

27. Kron, A.S.; Zengerer, V.; Bieri, M.; Dreyfuss, V.; Sostizzo, T.; Schmid, M.; Lutz, M.; Remus-Emsermann, M.N.P.; Pelludat, C. Pseudomonas orientalis F9 pyoverdine, safracin, and phenazine mutants remain effective antagonists against erwinia amylovora in apple flowers. Appl. Envsiron. Microbiol. 2020, 86. [CrossRef]

(C) 2020 by the authors. Licensee MDPI, Basel, Switzerland. This article is an open access article distributed under the terms and conditions of the Creative Commons Attribution (CC BY) license (http://creativecommons.org/licenses/by/4.0/). 